\title{
Loneliness: The Cause or Consequence of Peer Victimization in Children and Youth
}

\author{
Shireen Pavri*
}

\author{
California State University, Long Beach, College of Education, 1250 Bellflower Blvd. Long Beach, CA 90840-2201, \\ United States
}

\begin{abstract}
This article reviews the extant research literature on loneliness and peer victimization for children and youth, and explores the complex relationship between these two constructs. While lonely students who have few friends and receive limited peer support are vulnerable to being victimized by their peers, loneliness also emerges as a salient outcome of persistent and chronic peer victimization. The author discusses the phenomenon and incidence of bullying, the predictors of bullying and loneliness in children and youth, and reviews the literature associated with peer victimization in children and youth with disabilities, a population that is particularly vulnerable to being both the perpetrator and victim of bullying. The article concludes with a review of school-based intervention approaches to alleviate bullying in children and youth.
\end{abstract}

Keywords: Bullying, cognitions, loneliness, social anxiety, victimization, youth

Bullying in schools has increasingly been gaining attention as a cause for concern. Bullying is a stressor on school-aged children and youth that adversely impacts academic adjustment, psychosocial adaptation, and attitudes toward school [1, 2]. Bullying, also known as peer victimization, is found to cause isolation, fear, anxiety, depression, somatic complaints and health issues including headaches, stomachaches, and insomnia, along with long lasting psychological and somatic consequences [3-5]. Loneliness, social anxiety, and lower self-esteem are common outcomes for children and youth who have been bullied at school [5].

Peer victimization has been found to adversely impact long-term relationships and quality of life. In research conducted with over 8000 middle school students in Chile, Fleming and Jacobsen [6] found close to half (47\%) the students in the study reported being bullied over the past month, with $30 \%$ of the students indicating that they felt sad and hopeless over the past two weeks because of persistent bullying. While seventh and eighth graders reported higher levels of bullying, ninth graders reported increased loneliness, sleep difficulties, and suicidal thoughts as a result of being bullied. Bullying also increased the likelihood of suicidal ideation and planning for suicide. While more boys than girls reported being bullied, girls reported more vulnerability to the negative consequences of bullying, particularly depression, loneliness, sadness, hopelessness, and suicide ideation.

*Address correspondence to this author at the California State University, Long Beach, College of Education, 1250 Bellflower Blvd. Long Beach, CA 90840-2201, United States; E-mail: Shireen.Pavri@csulb.edu
The timing and duration of peer victimization mediates the loneliness experience. In a retrospective interview study with 884 adults (University students and teachers) who were victimized in primary and secondary school, Schafer, Korn, Smith, Hunter, Mora-Merchan, et al. [7] inquired into how school victimization impacted later life adjustment. They found adults who were victimized as children reported lower self-esteem, higher emotional loneliness, greater difficulties maintaining friendships, and were at higher risk for continued victimization as adults, than did peers who were not victimized at a young age. Victims who were bullied in secondary school also had a lower self-esteem in situations involving members of the opposite sex, and developed more fearful attachments.

Similar to the findings of Schafer et al. [7], Kochenderfer and Ladd [8] employed a longitudinal study to determine the impact of early peer victimization on later adjustment. Children who were regularly victimized while in kindergarten, reported higher levels of loneliness than did peers who were victimized later in life. Self-reports of these young victims indicated that their experience of loneliness grew more severe and chronic over time.

The current article reviews the extant research literature to explore the complex and inter-twined relationship between bullying and loneliness. While there is a vast literature base to support the claim that loneliness is a common outcome in students who are bullied $[6,9]$, the research also indicates that lonely children and youth are more susceptible to persistent bullying by their peers $[2,10$, 11], a phenomenon that maintains the student's victimized status and builds immunity to intervention. Peer-reviewed journal articles published between the years 2000-2014 (in English) were searched using the terms loneliness, "bullying", and children across ERIC, PsycArticles, and 
PsycInfo databases. Ancestral searches were also conducted that yielded a few additional studies. The author begins the article with an explanation of the phenomenon of bullying and how it relates to loneliness, and describes the global incidence of bullying across different cultures. Next, the author reviews the behavioral characteristics of bullies and victims, and the predictors of bullying and loneliness in children and youth. The phenomenon of victimization in children and youth with disabilities, a population that is particularly vulnerable to being both the perpetrator and victim of bullying, is discussed next. The article ends with a review of school-based intervention approaches to deal with bullying in children and youth.

\section{PEER VICTIMIZATION AKA BULLYING}

Olweus [12], a leading investigator in the field, defined bullying as aggressive behavior with the intent to harm another person. Bullying occurs intentionally and persistently over time, and in relationships characterized by an imbalance of power. Bullying usually takes one of three forms: (i) direct bullying which includes verbal or physical aggression toward another, (ii) indirect bullying includes using social relationships to harm the victim e.g., gossiping and spreading rumors, and intentional isolation, and (iii) cyberbullying that occurs via electronic communication through internet, phone, or social media [9]. Some consider peer sexual harassment to be bullying as well, with the intent to belittle and demean someone else based on gender [4].

Cyberbullying is of fairly recent origin, and is defined as an act of aggression conducted via electronic devices such as cell phones or computers [13]. The bullying occurs via media such as social networking, chat rooms, instant messaging, discussion boards, blogs, and websites, among other venues. In an investigation of the adverse impact of cyberbullying and traditional bullying, Jackson and Cohen [13] asked 192 children in grades 3-6 to complete selfreports and peer-reports of peer victimization, cyber victimization, and psychosocial functioning. Both types of victimization impacted psychosocial functioning, increased loneliness, and reduced optimism about peer relations and friendships. Cyber victimization was found to be highly prevalent, even among children as young as upper elementary school. While males are more likely to bear the brunt of traditional victimization than females, gender differences were not observed in instances of cyberbullying [13].

Students play the following roles when involved in the bullying dynamic: the bully who is the aggressor; the victim who is the target of bullies; the bully/victim who is both the aggressor and simultaneously the target of bullying by others; and the uninvolved student who may be a bystander [3]. Both the bully and bully-victim typically demonstrate aggressive behaviors such as a higher likelihood of fighting and carrying a weapon, and increased substance abuse [6].

\section{GLOBAL INCIDENCE OF BULLYING}

While bullying is a universal phenomenon that exists worldwide, there are cultural variations in the incidence of bullying across nations. National Center for Educational Statistics data indicate that between $28-32 \%$ of U.S. children report being victims of bullying in a 6-month period, $13 \%$ report being the perpetrator, and even more (a vast majority of students) report having experienced being a bystander to a bullying incident $[14,15]$. A Turkish study of bullying revealed similar findings with 742 middle school students, $21 \%$ of whom identified as victims, $4.6 \%$ as bullies, $6.5 \%$ as bully/victims, and $68 \%$ as uninvolved [3].

A comparison study of 28 North American and European countries surveyed 123,227 students ages 11, 13, and 15 years on their experience of bullying and 12 physical and psychological health symptoms that resulted [16]. Health symptoms included headaches, stomachaches, backaches, feeling low, bad temper, nervousness, sleeping difficulties, and dizziness. Additional symptoms assessed included loneliness, helplessness, feeling tired in the morning, and feeling left out of things [16]. The study revealed dramatic cultural variations in social norms around bullying across the 28 nations that participated in the study. Self reports of girls from Sweden who said they were bullied during the past month was as low as $5 \%$, while $41 \%$ of boys from Lithuania reported being bullied during the month the study was conducted. Gender differences while relatively few, confirmed extant research findings that boys experience a higher incidence of bullying than girls, and that bullying declines with age and grade level. Frequency of bullying had a more adverse effect on psychological as compared to physical symptoms. Boys and girls who reported feeling bullied at least weekly, reported the highest incidence of symptoms such as feeling lonely, helpless, and left out of things.

Data from another international study conducted with students in China, England, Ireland, Italy, Japan, Portugal, and Spain indicates similar variations in the incidence of bullying [17]. The incidence of victimization was at a high of $26 \%$ in Italy, yet as low as $5 \%$ in Ireland. The incidence of bullies ranged from a low of $2 \%$ in China, to a high of $17 \%$ in Spain. Of importance in this study is the differential impact of bullying on the victim vs. the perpetrator. Victims generally had fewer friends and were left alone to a greater extent at recess and playtime. Interestingly, different behaviors contributed to victimization vs. popularity across countries that were collectivist rather than individualistic in orientation. More cooperative behaviors were observed in collectivist cultures like China, with greater conflict evidenced in individualistic cultures such as England and the USA. Further, behaviors such as shyness were considered socially desirable and equated with popularity in China, but undesirable and associated with peer rejection in Canada [17].

Large-scale, longitudinal research studies conducted in the U.S. and Norway, suggest that the incidence of cyberbullying is considerably less than traditional bullying [9]. A longitudinal study conducted with 440,000 students in the U.S. from 2007 to 2010 indicated that an average of $17 \%$ of students reported being bullied verbally during this timeframe, while an average of $4.5 \%$ of students reported being cyberbullied [9]. Further, 9.6\% reported bullying others verbally, and $2.8 \%$ reported cyberbullying others. There was a high degree of overlap (around $88 \%$ ) of students who were verbally bullied and those who were cyberbullied. 
Using a Youth Internet Safety Survey (YISS-1) with 1501 kids (ages 10-17) in the U.S., Ybarra and Mitchell [18] found $15 \%$ of their sample reported being perpetrators of online harassment, and $7 \%$ of those surveyed reporting that they had been victims of cyberbullying. There were several psychological indicators of cyber bullies and victims that emerged from this study: $6 \%$ of online bullies (vs. $1 \%$ of non-bullies) had themselves been victims of physical or sexual harassment by an adult in the past year, $32 \%$ of the harassers (vs. $10 \%$ of the non-harassers) reported frequent substance abuse, and $50 \%$ of the harassers (vs. $30 \%$ of the non-harassers) reported being victims of traditional bullying, while $20 \%$ of perpetrators (vs. $4 \%$ of non-perpetrators) had themselves been victims of cyberbullying.

\section{BEHAVIORAL CHARACTERISTICS OF BULLIES AND VICTIMS}

Bullies are described as aggressive, disruptive, likely to start fights, while simultaneously displaying less cooperative behavior and lower self-esteem [17]. These behaviors interact with social risk factors to result in bullying. In contrast, victims are generally found to have poor social skills, tend to be shy and timid, have low self-esteem, and also display fewer cooperative behaviors, and report higher levels of loneliness $[2,17]$. Victims tend to be physically weaker and less popular than bullies, have lower self-esteem, and are often passive and submissive when bullied [4, 19]. Victims typically react either by withdrawing from the peer group or by demonstrating aggressive tendencies, sometimes becoming the bully-victim and earning the label of "provocative victim" [20].

While there are generally negative outcomes, there appears to be some resilience in youngsters who are peer victimized. For instance, while $77 \%$ of middle and high school students reported being victimized, only $14 \%$ reported significant traumatic effects of this victimization on their life adjustment [21]. Gender differences in resilience to bullying suggest that girls experience stronger academic support, peer support, and teacher support than boys, although boys have a more positive global, family, and peer self-esteem than do girls [22].

\section{PREDICTORS OF VICTIMIZATION AND LONELINESS}

Using a meta-analysis of 153 published studies, Cook and colleagues [1] identified thirteen predictors of peer victimization that were classified along two dimensions: individual factors and contextual factors. Individual predictors include: externalizing behaviors, internalizing behaviors, social competence, self-related cognitions (thought, beliefs and attitudes about themselves), and otherrelated cognitions (thought, beliefs, and attitudes about others). Contextual predictors include family/home environment, school climate, community factors, peer status (quality of relationships with peers), and peer influence (impact of peer relations on one's adjustment). The individual variables that emerged as the strongest predictors of bullying included externalizing behaviors and otherrelated cognitions [1]. Age, internalizing behaviors, and selfrelated cognitions were least likely to predict bullying. Confirming the findings from other research, Cook et al. found peer status and social competence emerged as the most likely predictors of being a victim of bullying. Self-related cognitions and social competence emerged as key predictors of students being bully-victims, although other variables like comorbid externalizing and internalizing behavior and otherrelated cognitions also contributed significantly to this status. Amongst contextual variables, both peer influence and community factors were highly predictive of bullying behavior, while peer status and family environment emerged as least influential variables in predicting bullying behavior [1].

Loneliness has consistently been viewed as an indicator of problematic peer relationships [2,20], and has emerged as one of the most reliable and sustained predictors of peer victimization in youngsters $[3,5]$. Children who move from non-victimized to victimized status experience an increase in loneliness, yet no accompanying decrease in loneliness is reported by children who are no longer victimized $[2,13]$.

In a large-scale longitudinal study conducted with 388 students in KG, $1^{\text {st }}, 2^{\text {nd }}$ and $3^{\text {rd }}$ grades, Kochenderfer-Ladd and Wardrop [2] investigated adjustment trajectories of children who were peer victimized. Key variables of loneliness and social satisfaction were measured and the authors found that the trajectories differed on these two forms of psychosocial maladjustment. Children who were chronically victimized by peers reported increasing and stable levels of loneliness over time, and also reported being sad and alone. Yet, victimized children were not always unhappy with their social situation. Some of them reported being satisfied with their peer relationships. It appears that youngsters who are victimized may reap the social benefits of companionship and guidance from peers, but may not enjoy the emotional benefits of validation and intimacy that result in elevated experiences of loneliness.

There is some evidence to indicate that a child's sense of control over the victimization affects his experience with loneliness and hopefulness. In a study with 110 students aged 8-12 in Scotland schools, Catterson and Hunter [23] found that a perceived sense of control over victimization helped alleviate loneliness. Children reporting higher loneliness and higher victimization gave themselves lower appraisals of control. Yet, children who rated themselves as having higher perceived control over the social situation were better able to adjust with loneliness. Perceived control emerged as a predictor of loneliness, though self-blame and external threats did not.

Children's solitary behavior is correlated with loneliness and peer victimization $[2,11,24]$. It could be that solitary children with fewer friends are the target of bullies or that victimized children withdraw from social contact and consequently have fewer friends. It may also be that loneliness is a personality trait found in victims of bullying, which once detected by the bully, increase the probability of victimization [10]. This research confirms the findings of Hodges and Perry [25] that adolescents who are rejected by peers and who have smaller social networks are at risk for victimization. On the other hand, adolescents with a large number of friends, who enjoy strong reciprocal friendships, are typically less likely to be victimized. 
The self-related cognitions that students develop as a result of victimization impact loneliness. Children and adolescents who arrive at critical self-referent attributions (e.g., "I am no fun to play with") when interpreting peer behavior cues are likely to have high levels of withdrawn behavior, including loneliness and depressive symptoms, particularly if they had been victimized by peers [26]. Highly critical self-referent attributions were correlated with high peer rejection, and with internalizing behaviors [26]. The authors found boys with critical self-referent attributions manifested more depressive symptoms than girls in this subgroup. Children tend to make negative attributions for peer behavior and then withdraw from the social situation, thereby often making themselves even more a target of peer victimization.

\section{EXPERIENCES OF BULLYING AND LONELINESS IN CHILDREN WITH DISABILITIES}

Research findings indicate that children and youth with disabilities are more vulnerable to being both the perpetrator of bullying and also the victim [27-29]. Whitney, Nabuzoka and Smith [30] found $67 \%$ of students with special needs were bullied in contrast to $25 \%$ of their peers without disabilities. They found $55 \%$ of students with mild learning difficulties, and $77 \%$ of students with moderate learning difficulties experienced peer victimization. Saylor and Leach [31] found students with disabilities were more fearful of their safety at school, concerned about being physically injured by peers, and anxious about being harassed, than was true for peers without disabilities.

A National Survey of Children's Health indicates that youngsters with emotional, behavioral or developmental problems are more likely to be the bully, victim, or bullyvictim than students without special health care needs [32]. Children with clinically significant behavioral problems such as conduct problems, hyperactivity, emotional difficulties and peer relationship difficulties are disproportionately affected by bullying [33]. Additionally, children with observable disabilities are also more likely to be victims [34]. Perpetration may result as a reaction to prolonged victimization amongst youngsters with disabilities [34].

Students with disabilities experience greater social isolation, fewer reciprocated friendships, reduced peer social support, and consequently are at higher risk for being bullied $[35,36]$. Students with autism often have difficulty reading social cues and regulating emotions, which increases the likelihood of being victimized [29]. Their cognitive and social relational difficulties cause barriers in recognizing that a problem exists, for which the student should seek help. As a result, youngsters with autism often do not receive much needed social support from classmates, parents, teachers, and friends, thereby increasing social isolation and their vulnerability to victimization and loneliness [36].

Children with learning disabilities are found to be more aggressive and impulsive, have poor social skills, and are more likely than peers to be both the perpetrator and the victim of bullying [35]. Reiter and Lapidot-Lefler [37] found $83 \%$ of middle school students with mild developmental and intellectual disabilities attending special schools in Israel reported experiencing peer victimization. This study revealed that students who were hyperactive and exhibited behavior problems were more likely to be bullies, while students with emotional and interpersonal relationship problems were more likely to be victimized.

Among students who are deaf or hard of hearing, difficulties in communication impact their peer relationships and emotional adjustment, often aggravated by bullying that results in social isolation and loneliness [38]. Kent [39] conducted a study with 5211,13 , and 15 year-old mainstreamed students in New Zealand who were deaf or hard of hearing, and compared them with 470 hearing peers matched for gender, age, and ethnicity. They used a measure of health-related outcomes, the Health Behavior in SchoolAged Children (HBSC) instrument to investigate feelings of alienation, health behaviors, and attitudes. Students who identified as hard of hearing reported more episodes of bullying, and corresponding higher levels of loneliness and experiences of being alone, when compared to their typical peers. While there were no differences in the extent to which girls who did and did not identify as hard of hearing liked school, boys who did not self identify reported far more positive feelings about school than did boys who identified as hard of hearing.

Preliminary evidence suggests that children and youth with disabilities are bullied at higher frequencies when they attend school in more restrictive educational placements [27, 34]. Rose et al. [27] found that more restrictive educational placements were a predictor of increased bullying and fighting behavior. Middle school students with disabilities in self-contained learning environments engaged in higher rates of fighting, bullying perpetration, and victimization than their peers with disabilities in inclusive environments, and their typically developing peers.

This frequent and persistent victimization amongst students with disabilities causes elevated levels of social anxiety, internalizing problems, and on occasion, selfinjurious behaviors [40]. In an attempt to put an end to the rampant bullying of students with disabilities, the U.S. Office of Special Education and Rehabilitative Services (OSERS) has issued strongly worded guidance to educators (http://www.stopbullying.gov/blog/2013/08/23/keepingstudents-disabilities-safe-bullying). Bullying of children and youth based on their disability, if it denies them equal opportunity to education, is considered "disability harassment" per the Americans with Disabilities Act, and must be addressed by the school.

\section{INTERVENTIONS TO ALLEVIATE BULLYING AND LONELINESS}

Due to its detrimental effects, federal and state governments are increasingly taking a leading role in developing initiatives to stop bullying in schools. For instance, the U.S. Secret Service, in collaboration with the U.S. Department of Education, has initiated the Safe School Initiative, and most states have anti-bullying legislation in place to curb school violence and bullying [15]. Strategies include raising awareness of the bullying phenomenon amongst staff, students, and parents, and creating behavioral norms and rules to guide student behavior. 
The literature indicates that most efforts to prevent bullying in schools employ universal interventions such as anti-bullying rules that are integrated into the formal and informal school curriculum, generalized supports available to students, and clear procedures for reporting bullying incidents [35]. These primary interventions affect all students at a school, and are effective with $80-90 \%$ of the population of students [1]. Olweus [19] suggests four guiding principles in designing such universal interventions for bullying in schools: (1) establishment of a caring and positive school environment characterized by involved adults, (2) clear boundaries for acceptable and unacceptable behavior, (3) consistent enforcement of school rules using positive techniques, and (4) adults in the school and home viewed as authority figures who can both support and protect the victim.

There is need to tailor the secondary and tertiary interventions for students who engage in persistent bullying or are long-term victims of bullying, to meet their unique situation within a particular social environment. As an example, aggression replacement training may be used to deal with a bully who engages in frequent aggressive behavior with peers. The author discusses two interventions in this next section, that schools may adopt to alleviate bullying and loneliness.

\section{SOCIAL SUPPORT INTERVENTIONS}

Peer Social Support. Given that solitary behavior and a lack of friends are risk factors for bullying and loneliness, many intervention approaches focus on training peers to provide social support for the child who is victimized [20]. Social support from peers makes for a positive social environment and has been found to increase overall emotional wellbeing and academic adjustment in the victim [41], and reduce internalizing behaviors and improve peer relationships [42, 43]. The Support Group Approach to bullying comprises of the victim identifying friends who they would like to include in their support group, which once formed helps find ways to support the victim from further episodes of bullying [44].

It is posited that when victims themselves engage in prosocial behavior, they are able to maintain positive peer relationships and get their social needs met, thereby tending to be less lonely [20]. These findings highlight the protective function served by prosocial behaviors that act as a buffer against loneliness, regardless of peer victimization. Griese and Buhs [20] concluded that though prosocial behaviors predicted lower loneliness in victimized boys, peer support outweighed prosocial behavior as a buffer against loneliness for girls.

Adult Supports. Teachers and parents play a critical role in protecting youngsters from psychosocial consequences of peer victimization. The research indicates mixed results regarding the extent to which students approach adults in seeking assistance when they are bullied. Humphrey and Symes [36] found students with autism were most likely to seek assistance from teachers and other school staff when they experienced peer aggression, though teacher interventions did not always result in productive outcomes. Interestingly, students did not reach out to their parents for assistance with school-related bullying, assuming that parents had no direct way to help them.

Restorative programs call for adults to demonstrate genuine interest in the bully and the victim, and require that adults establish clear expectations for desired behaviors. Adults are urged to use a positive discipline approach and not punishment, when rules and policies are broken, and adults should serve as role models for peer interactions [45]. Berguno and colleagues [24] found that most students reported bullying incidents to teachers at school, yet found that teacher interventions did not alleviate loneliness and often increased social isolation. Teachers intervened only 18 of the 29 times that bullying occurred (62\%), and only 3 of these 18 students reported lasting benefits of teacher intervention on their social lives. Students reported that teachers typically had one of two reactions to their complaints; they either took no action, or they punished the bully. The latter consequence often increased the extent to which the target student was victimized. When teachers adopted restorative and interpersonal solutions, however, the bullying was reported to decrease [24].

Similar findings emerged in a longitudinal study of loneliness and its impact on wellbeing in 119 girls in grades 1-8 in Norway, using the School Wellbeing Questionnaire that probed academic problems, victimization, and loneliness. Lohre, Kvande, Hjemdal, and Lillefjel [46] asked students to state the person they could go to for assistance when they had difficulties. Parents were most frequently cited as a trusted other by over $80 \%$ of respondents, with a class advisor emerging as the next most frequently cited trusted other. Students cited their peers as the third most frequently sought source of support. Lohre at al. explored the relationship and impact of the trusted other on loneliness and school wellbeing, and found higher levels of loneliness were correlated with lower school wellbeing a year later. When girls who were lonely were able to seek the advice of class advisors, they appeared more resilient and reported similar levels of school wellbeing as non-lonely girls when assessed a year later.

In addition to gender, age differences were found in coping strategies used. Younger children in primary school were more likely to seek the assistance of an adult in dealing with bullying, while secondary aged students were 1.6 times more likely to do nothing about the bullying incident [47].

\section{ANTI-BULLYING PROGRAMS}

Anti-bullying curriculum and programs are a proactive approach to prevent bullying. Such programs typically provide students with the opportunity to develop conflict resolution and peer mediation skills, and to learn ways to diffuse potentially threatening situations. There are several "off-the-shelf" anti-bullying programs for school use, such as Conflict Resolution Education [48], and Olweus Bullying Prevention Program [49], amongst other curricula.

It takes a lot more than token application of these antibullying programs for a prescribed duration, such as an hour a week, to see any significant impact. The basic tenets of these programs need to become a part of the school climate and these principles must be reinforced daily by caring adults throughout the school day. For instance, Saylor and 
Leach [31] assessed the impact of an inclusive programming opportunity, Peer EXPRESS (Experiences to Promote Recreation, Exposure, and Social Skills) that created opportunities for students with disabilities to engage in social activities with typically developing same-age peers, a year after it was implemented. While there was a reduction in the perceived fear of social victimization as a result of this peer support, close bonds were not developed with these token inclusion activities, and students with disabilities reported reduced classmate support over the school year.

Ttofi and Farrington [50] investigated the effectiveness of anti-bullying programs. A meta-analysis of 30 schoolbased programs used worldwide indicated a 20-23\% reduction in bullying and $17-20 \%$ reduction in victimization in intervention as compared to control schools. Comprehensive programs that adopt a multi-faceted approach to bullying had maximum benefits in reducing bullying. Parent training and information, playground supervision, disciplinary methods including classroom rules and classroom management, school conferences, and working with peers emerged as key components of effective anti-bullying programs in the schools [50].

Anti-bullying policy and practices in the school should include (i) an assessment of the prevalence of bullying at the school, (ii) a school-wide anti-bullying policy that defines bullying, clarifies the rights and responsibilities of school personnel, establishes procedural guidelines to deal with bullying, clarifies the consequences of bullying, and adopts the use of prevention strategies, (iii) staff training, (iv) evidence-based programming, (v) developing local leadership for anti-bullying efforts, and (vi) using appropriate disciplinary practices [51].

Solution focused brief therapy is another anti-bullying approach that has been used in public school settings [44]. Attention is focused on the solutions and not on the problems by targeting past successes, positive skills, and preferred outcomes. The facilitator begins the session with general conversation that does not relate to the problem at hand and that enhances the victim's self-esteem. The victim is then asked to provide a scaled rating (e.g., on a 1-10 scale) of where she believes she is at the present time, while the facilitator discusses the skills the victim used to deal with her difficulties to reach that point on the scale. The facilitator then focuses on the exceptions, and inquires into what occurred when the problem was not manifested. Finally, with a focus on future preferences, the facilitator encourages the victim to describe a life where this problem is not manifested, and probes details related to such a situation [44].

It is clear that preventing bullying in schools requires a coordinated and committed approach with clear rules, guidelines for reporting bullying incidents, and staff, parent, and peer training. Additional research is needed on evidencebased anti-bullying programs that are effective in preventing bullying in schools.

\section{CONCLUSION}

Bullying has been described as a relationship problem; one characterized by deleterious consequences for both the perpetrator and the victim $[9,16]$. Loneliness emerges as a stable indicator of victimization in children and youth, with lonely children having few friends, reduced peer support, less perceived control over their victimization, and greater vulnerability to being picked on by bullies $[2,10,20]$. Additionally, chronic and persistent bullying, particularly when it occurs at an early age, has been found to cause intense loneliness and later life adjustment difficulties including reduced self-esteem and social anxiety [2, 7]. Although a large majority of children and youth report having been bullied or having been a bystander to a bullying incident, research indicates that certain groups of students e.g., children with disabilities, are more vulnerable to peer victimization [34]. Peers standing up in support of the victim can reverse some of the adverse effects of bullying. Parents and teachers play a critical role as well in preventing bullying, by demonstrating caring authority and using positive discipline approaches [50].

\section{CONFLICT OF INTEREST}

The authors confirm that this article content has no conflict of interest.

\section{ACKNOWLEDGEMENTS}

Declared none.

\section{REFERENCES}

[1] Cook CR, Williams K, Guerra NG, Kim TE, Sadek S. Predictors of bullying and victimization in childhood and adolescence: A metaanalytic investigation. Sch Psychol Q 2010; 25(2): 65-83.

[2] Kochenderfer-Ladd B, Wardrop JL. Chronicity and instability of children's peer victimization experiences as predictors of loneliness and social satisfaction trajectories. Child Dev 2001; 72(1): 134-51.

[3] Atik G, Guneri, OY. Bullying and victimization: Predictive role of individual, parental, and academic factors. Sch Psychol Int 2013; 34(6): 658-73.

[4] Beaty LA, Alexeyev EB. The problem of school bullies: What the research tells us. Adolescence 2008; 43: 1- 11.

[5] Hawker D, Boulton M. Twenty years' research on peer victimization and psychosocial maladjustment: A meta-analytic review of cross-sectional studies. J Child Psychol Psychiatry 2000; 41(4): 441-55.

[6] Fleming LC, Jacobsen KH. Bullying and symptoms of depression in Chilean middle school students. J Sch Health 2009; 79:130-37.

[7] Schafer M, Korn S, Smith $\mathrm{P}$, et al. Lonely in the crowd: Recollections of bullying. Br J Dev Psychol 2004; 22: 379- 94.

[8] Kochenderfer BJ, Ladd GW. Peer victimization: Cause or consequence of children's school adjustment difficulties? Child Dev 1996a; 67: 1305-17.

[9] Olweus D. School bullying: Development and some challenges. Ann Rev Clin Psychol 2013; 9: 751-80.

[10] Cava MJ, Musitu G, Murgui S. Individual and social risk factors related to overt victimization in a sample of Spanish adolescents. Psychol Rep 2007; 101: 275-90.

[11] Kochenderfer BJ, Ladd GW. Peer victimization: Manifestations and relations to school adjustment in kindergarten. J Sch Psychol 1996b; 34: 267-83.

[12] Olweus, D. Bullying at School. Oxford, UK: Blackwell 1993.

[13] Jackson CL, Cohen R. Childhood victimization: Modeling the relation between classroom victimization, cyber victimization, and psychosocial functioning. Psychol Pop Media Cult 2012; 1(4): 254-69.

[14] Robers S, Zhang J, Truman J, Snyder TD. Indicators of school crime and safety: 2010 [Internet]. Washington, DC: Government Printing Office; 2010. Available from http://www.nces.ed.gov/pubs2011/2011002.pdf 
[15] Rose C, Espelage D, Aragon S, Elliott J. Bullying and victimization among students in special education and general education curricula. EEI 2011; 21:2-14.

[16] Due P, Holstein B, Lynch J, et al. Bullying and symptoms among school-aged children: International comparative cross-sectional study in 28 countries. Eur J Pub Health 2005; 15: 128-32.

[17] Eslea M, Menesini E, Morita Y, et al. Friendship and Loneliness among bullies and victims: Data from seven countries. Aggress Behav 2003; 30: 71- 80 .

[18] Ybarra ML, Mitchell J. Online aggressor/targets, aggressors and targets: A comparison of associated youth characteristics. J Child Psychol Psychiatry 2004; 45: 1308-16.

[19] Olweus D. Bully/victim problems in school: Facts and intervention. Eur J Psychol Edu 1997; 12(4): 495-510.

[20] Griese ER, Buhs ES. Prosocial behavior as a protective factor for children's peer victimization. J Youth Adolesc 2014; 43: 1052-65.

[21] Hoover JH, Oliver RL, Hazler RJ. Bullying: Perceptions of adolescent victims in the Midwestern U.S.A. Sch Psychol Int 1992; 13: 5-16.

[22] Brighi A, Guarini A, Melotti G, Galli S, Genta M. Predictors of victimisation across direct bullying, indirect bullying and cyberbullying. J Emot Behav Disord 2012; 17(3-4): 375-88.

[23] Catterson J, Hunter S. Cognitive mediators of the effect of peer victimization on loneliness. Br J Educ Psychol 2010; 80: 403-16.

[24] Berguno G, Leroux P, McAinsh K, Shaikh S. Children's experience of loneliness at school and its relation to bullying and the quality of teacher interventions. Qual Rep 2004; 9: 483-99.

[25] Hodges E, Perry D. Victims of peer abuse: an overview. J Emot Behav Prob 1996; 5: 23-8.

[26] Prinstein M, Cheah C, Guyer A. Peer victimization, cue interpretation, and internalizing symptoms: Preliminary concurrent and longitudinal findings for children and adolescents. J Clin Child Adolesc Psychol 2005; 34: 11-24.

[27] Norwich B, Kelly N. Pupil's views on inclusion: Moderate learning difficulties and bullying in mainstream and special schools. $\mathrm{Br}$ Educ Res J 2004; 30: 43-65.

[28] Rose CA, Monda-Amaya LE, Espelage DL. Bullying perpetration and victimization in special education: a review of the literature. Remedial Spec Educ 2010; 32: 114-30.

[29] Schroeder J, Cappadocia C, Bebko J, Pepler D, Weiss J. Shedding light on a pervasive problem: A review of research on bullying experiences among children with autism spectrum disorders. J Autism Dev Disord 2014; 44: 1520-34.

[30] Whitney L, Nabuzoka D, Smith PK. Bullying in schools: Mainstream and special needs. Supp Learn 1992; 7(1): 3-7.

[31] Saylor C, Leach J. Perceive bullying and social support in students accessing special inclusion programming. J Dev Phys Disabil 2009; 21: 69-80.

[32] Van Cleave J, Davis MM. Bullying and peer victimization among children with special health care needs. Pediatrics 2006; 118:121219.

[33] Woods S, Wolke D. Direct and relational bullying among primary school children and academic achievement. J Sch 2004; 42: 13555.
[34] Rose CA, Espelage DL, Monda-Amaya LE. Bullying and victimization rates among students in general and special education: A comparative analysis. Educ Psychol 2009; 29: 761-76.

[35] Cummings J, Pepler D, Mishna F, Craig W. Bullying and victimization among students with exceptionalities. Except Educ Can 2006; 16(3): 193-222.

[36] Humphrey N, Symes W. Responses to bullying and use of social support among pupils with autism spectrum disorders (ASDs) in mainstream schools: a qualitative study. J Res Spec Educ Needs 2010; 10: 82-90.

[37] Reiter S, Lapidot-Lefler N. Bullying among special education students with intellectual disabilities: Differences in social adjustment and social skills. Int J Dev Disabil 2007; 45(3): 174-81.

[38] Kiff P, Bond D. The inner life of deaf children. In Varma V, ed. The inner life of children with special needs. Gateshead: Athenaeum Press 1996; p. 15-26.

[39] Kent BA. Identity issues for hard of hearing adolescents aged 11, 13, and 15 in mainstream settings. J Deaf Stud Deaf Educ 2003; 8: 315-24.

[40] Zablotsky B, Bradshaw CP, Anderson C, Law PA. The association between bullying and the psychological functioning of children with autism spectrum disorders. J Dev Behav Pediatr 2013; 34(1): $1-8$.

[41] Wang J, Iannotti RJ, Luk JW. Peer victimization and academic adjustment among early adolescents: Moderation by gender and mediation by perceived classmate support. J Sch Health 2011; 81(7): 386-92.

[42] Davidson L, Demaray M. Social support as a moderator between victimization and internalizing-externalizing distress from bullying. Sch Psychol Rev 2007; 36(3): 383-405.

[43] Holt M, Espelage D. Perceived social support among bullies, victims, and bully-victims. J Youth Adoles 2007; 36(8): 984-94.

[44] Young S, Holdorf G. Using solution focused brief therapy in individual referrals for bullying. Educ Psychol Pract 2003; 19(4): 271-82.

[45] Meyer L, Evans I. The teachers guide to restorative classroom discipline. Thousand Oaks, CA: Corwin 2012.

[46] Lohre A, Kvande M, Hjemdal O, Lillefjel M. A two year perspective: Who may ease the burden of girls' loneliness in school? Child Adolesc Psychiatry Ment Health 2014; 8: 10.

[47] Hunter SC, Borg MG. The influence of emotional reaction on help seeking by victims of school bullying. Educ Psychol 2006; 26: 81326.

[48] Garrard WM, Lipskey MW. Conflict resolution education and antisocial behavior in U.S. schools: A meta-analysis. Conflict Resol Q 2007; 25: 9-38.

[49] Olweus D. A profile of bullying at school. Educ Leadership 2003; 60(6): $12-17$

[50] Ttofi M, Farrington D. What works in preventing bullying: Effective elements of anti-bullying programmes. J Aggress Conflict Peace Res 2009; 1(1): 13-24.

[51] Nickerson AB, Cornell DG, Smith JD, Furlong M. School antibullying efforts: advice for education policymakers. J Sch Viol $2013 ; 12: 268-82$. 